\section{Patent threat to research}

Sir - The proposed Directive to the European Parliament and Council of the European Union on biotechnological patents $(95 / 0350(\mathrm{COD}))$, currently under discussion, poses a threat to the future of scientific and medical research. Its potential consequences are as serious as those arising from the sweeping patent granted to the US company Biocyte on the use of all human blood cells from the umbilical cord of a newborn. This is being disputed by US and European medical groups because it threatens the free use of such cells for transplant purposes and in research (see E. Gluckman et al., Nature 382, 108; 1996).

The directive extends this type of commercial constraint on scientific and medical work to all organisms. A company has only to make use of a "microbiological process" in obtaining plants or animals to be able to patent them. It would then own them and be able to demand patent rights from anyone else wishing to work on them. The directive further states that the patent entitles the holder to prohibit third parties from exploiting them for industrial and commercial purposes. Applicants for research grants in the United Kingdom are now required to name the beneficiaries of their research. Most state-supported research in biotechnology can therefore be held to be for industrial and commercial purposes, and the patent holder could prohibit it even if patent rights are paid for use of the material.

Advances in biotechnology are already patentable under European patent law. What is at issue is whether these patents should be very much broader in scope than those in other fields, and, in particular, whether

someone who isolates and characterizes been applied in chemistry, the elements directive does refer to "elements of plants and animals". an important role to play, but we do not accept the claim in the directive that the benefits we can expect are so vital and so there are dangers to be recognized and safeguards to be put in place, and by and useful contribution to medicine and agriculture, the present directive from Brussels succeeds only in threatening the very foundations of scientific research promising lines of enquiry. Warwick); Brian Goodwin* (Department of MK76AA, UK; e-mail:b.c.goodwin@open.ac.uk); Mae-Wan Ho (Biology, Open University); Jacqueline McGlade (Biological Sciences, Botanic Gardens, Kew); Peter Saunders (Mathematics, Kings College London); David University of Warwick)

*To whom correspondence should be addressed. natural material should be able to patent not just the method by which this was done but also the material itself. If this principle had would have been patented, and indeed, the

We do not doubt that biotechnology has urgent that special restrictions are called for. Moreover, as with all industrial innovations, impeding research the new law would make it less likely that this will happen. Instead of helping biotechnology to make a responsible free access to material and freedom to pursue

Howard Dalton (Biological Sciences, University of Biology, Open University, Walton Hall, Milton Keynes University of Warwick); Ghillean Prance (Royal Sherratt (Microbiology, University of Oxford); John Maynard Smith (Biological Sciences, University of Sussex); Roger Whittenbury (Biological Sciences,

various aspects of the book became four in the version printed, and were inverted: thus a 2 ('excellent' on the scale I was asked to use) became ${ }^{* *}$ (indicating only fair).

Overall, the result was unfair to the authors. I hope that the sales of this worthy volume are not adversely affected by this unfortunate occurrence.

\section{David M. J. Lilley}

Department of Biochemistry,

University of Dundee, Dundee DDI 4HN, UK

e-mail:dmjlilley@bad.dundee.ac.uk

negative comment, about the biological

relevance.

My original sentence, "Triple-Helical Nucleic Acids presents a comprehensive and authoritative review of the current state of knowledge about most aspects of these novel structures, covering structural, molecular recognition and physical chemical aspects of triplex DNA in impressive detail", was shorn of all its positive adjectives. Moreover, the five 'scores' according to which I was asked to rate later and without attribution), the Pines-Shaham starquake theory...". By this statement, Anderson is implying plagiarism. That this is untrue can be simply proved by looking at the literature in question. Bak used the preprints that were subsequently published in refs 2 and 3. In ref. 2 (which derives the pulsar scaling law directly from original radioastronomical data), attribution is given in the following words: "We adopt the crust cracking model for pulsar glitches (M. Ruderman, Ap. J. 366, 1991, 261; 382, 1991, 576, 587)". The Ruderman papers quoted are the original papers that introduced the concept of neutron-star surface platelets. In ref. 3 (which presents the mass-accretion stress mechanism for pulsar glitches, which Bak, in his book, calls "speculative"), the attribution is given by: "This may be explained by the fact that pulsar glitches are starquakes (M. Ruderman, Nature 223, 1969, 597; G. Baym and D. Pines, Ann. Phys. 66, 1971, 816)". Anderson's name does not appear, nor should it.

Peter Morley

Department of Physics,

University of Texas,

Austin, Texas 78712, USA

e-mail:morley@linux.ph.utexas.edu

1. Anderson, P. W. Nature 383, 772 (1996)

2. Morley, P. D. \& Garcia-Pelayo, R. Europhys. Lett. 23, 185-189 (1993). 3. Morley, P. D. Astron. Astrophys. 313, 204-208 (1996).

Philip Anderson replies - The words "without attribution" referred only to the book's author, Per Bak, and not to the original authors, whose work I had not seen, and who I could assume gave proper references.

But my other comment remains valid. When Ruderman, Pines and Shaham abandoned the starquake theory, it was not to leave the field but because they felt the theory was physically untenable for almost all glitching pulsars. The amount of energy of elastic deformation that can be released in the well-understood Coulomb solid of the pulsar crust is many orders of magnitude below the size of a typical Vela-type glitch. After a brief flirtation with possible "core" solids they enthusiastically welcomed my suggestion of superfluid "vorticity jump" events, and various of the group Ruderman, Pines, Shaham, Alpar and Anderson published a series of papers together on this quite successful scenario. If we had yet heard of self-organized criticality, our discussion of glitch statistics might have been much improved, but we were a decade or two too early. We would welcome such an improvement of the model by Peter Morley. Philip W. Anderson

Joseph Henry Laboratories of Physics,

Princeton University,

Princeton, New Jersey 08544, USA

e-mail:esz@pupgg.princeton.edu 